\title{
IS6I I0 Restriction Fragment Length Polymorphism Typing of Drug-resistant Mycobacterium tuberculosis Strains from Northeast South Africa
}

\author{
Ezekiel Green 1,2, Lawrence C. Obi ${ }^{3}$, Anthony I. Okoh², Maphoshane Nchabeleng ${ }^{4}$, Babsie E. de \\ Villiers ${ }^{4}$, Tomas Letsoalo ${ }^{4}$, Anwar A. Hoosen ${ }^{5}$, Pascal O. Bessong ${ }^{1,6}$, Roland N. Ndip ${ }^{2,7}$ \\ 'School of Mathematics and Natural Sciences, Department of Microbiology, University of Venda, Private Bag X5050, \\ Thohoyandou 0960, South Africa; ${ }^{2}$ Department of Biochemistry and Microbiology, Faculty of Science and Agriculture, \\ University of Fort Hare, Private Bag X1314, Alice 5700, South Africa; ${ }^{3}$ Division of Academic Affairs, University of Fort Hare, \\ Alice 5700, South Africa; ${ }^{4}$ Department of Microbiological Pathology, NHLS/University of Limpopo, Medunsa campus, Pretoria, \\ South Africa; ${ }^{5}$ Department of Medical Microbiology, Faculty of Health Sciences, University of Pretoria/NHLS, Pretoria, South \\ Africa; ${ }^{6}$ AIDS Virus Research Laboratory, Department of Microbiology, University of Venda, South Africa; ${ }^{7}$ Department of \\ Microbiology and Parasitology, University of Buea, Box 63, Buea, Cameroon
}

\section{ABSTRACT}

Tuberculosis (TB) remains a deadly infectious disease affecting millions of people worldwide; $95 \%$ of TB cases, with $98 \%$ of death occur in developing countries. The situation in South Africa merits special attention. A total of 21,913 sputum specimens of suspected TB patients from three provinces of South Africa routinely submitted to the TB laboratory of Dr. George Mukhari (DGM) Hospital were assayed for Mycobacterium tuberculosis (MTB) growth and antibiotic susceptibility. The genetic diversity of 338 resistant strains were also studied. DNA isolated from the strains were restricted with $P v u$ II, transferred on to a nylon membrane and hybridized with a PCR-amplified horseradish peroxidase 245 bp IS6110 probe. Of the 338 resistant strains, $2.09 \%$ had less than 5 bands of IS6110, and $98 \%$ had 5 or more bands. Unique restriction fragment length polymorphism (RFLP) patterns were observed in $84.3 \%$ of the strains, showing their epidemiological independence, and $15.7 \%$ were grouped into 22 clusters. Thirty-two strains $(61.5 \%)$ from the 52 that clustered were from Mpumalanga, 16/52 (30.8\%) from Gauteng, and 4/52 (9.6\%) from Limpopo province. Clustering was not associated with age. However, strains from male patients in Mpumalanga were more likely to be clustered than strains from male patients in Limpopo and/or Gauteng province. The minimum estimate for the proportion of resistant $\mathrm{TB}$ that was due to transmission is $9.06 \%(52-22=30 / 331)$. Our results indicate that transmission of drug-resistant strains may contribute substantially to the emergence of drug-resistant tuberculosis in South Africa.

Key words: Drug resistance; Epidemiology; IS6110; M. tuberculosis; PCR-RFLP; South Africa

\section{INTRODUCTION}

Tuberculosis (TB) remains a deadly infectious disease affecting millions of people worldwide; $95 \%$ of TB cases, with $98 \%$ of deaths, occurr in developing countries (1). Approximately one-third of the world's population is infected with tuberculosis, and 2 million people die of the disease every year

Correspondence and reprint requests:

Prof. R.N. Ndip

Department of Biochemistry and Microbiology

University of Fort Hare

Private bag X1314, Alice 5700

South Africa

Email: rndip@ufh.ac.za; ndip3@yahoo.com Fax: +27(0) 4066531730
(2). South Africa is a country with a high incidence of TB-600 cases per 100,000 population in 2005 (3), 550 cases per 100,000 population in 2003, and 718 cases per 100,000 population in 2004 $(4,5)$. During the study period, the cases of drug resistance increased from 156 per 100,000 in 2004 to 177 per 100,000 in 2006 in Mpumalanga, and from 58 to 84 per 100,000 in Limpopo. However, Gauteng showed a high number of drug-resistant cases with an increase from 662 in 2004 to 794 per 100,000 in 2006 (3).

World Health Organization recommends standardized TB treatment regimens based on short-course chemotherapy. The anti-TB drug regimen recommended for the treatment of new cases consists of 
a two-month administration of isoniazid (INH), rifampicin (RIF), pyrazinamide (PZA), and ethambutol (EMB), followed by a continuation phase of INH/RIF and/or EMB for four months (2). However, this treatment is usually effective against MTB strains that have never been exposed to anti-TB drugs for more than 30 days (6) and against strains that do not possess drug-resistant mechanisms. For many years, Direct Observation of Treatment (DOT) has been promoted by the World Health Organization (WHO) as one of the five components of a wider strategy called Directly Observed Treatment, Short Course (DOTS) to tackle the resurgence of TB throughout the world (7). Direct observation by health workers while patients take their tablets aims to improve adherence to therapy and completion of treatment. Specific therapy for patients with drug-resistant tuberculosis is included in DOTS-plus. A surge in drug-resistant tuberculosis in several parts of the world requires effective implementation of the DOTS-plus strategy to prevent the occurrence of new multidrug-resistant (MDR) TB cases and to reduce transmission of MTB.

Resistance to antibiotics in MTB occurs due to genomic mutations in certain genes, such as katG for INH resistance and $r p o B$ for RIF resistance (8). Therefore, MTB will benefit from increased mutation rate. Unlike other pathogens with MDR pathotypes, such as transposable elements, plasmidmediated mechanisms of resistance have not been reported in MTB $(9,10)$.

In recent years, treatment of TB has become complicated by increasing emergence of drug-resistant M. tuberculosis (DR-TB) (11). The proportion of MDR-TB strains in South Africa rose from 1.1\% in 2004 to 1.9\% in 2006 (3). Extremely drug-resistant (XDR) TB strains have also been reported in the country (12).

Analysis of the spread and transmission of DRTB strains, using molecular methods, has been reported (13). Techniques, such as restriction fragment length polymorphism (RFLP) and insertion sequence 6110 (IS6110), have been used in reliably differentiating $M$. tuberculosis isolates $(14,15)$, and IS6110 has been suggested as a standard tool for characterization of isolates. IS6110 fingerprinting has also been used successfully to confirm laboratory cross-contaminations and to trace small-scale outbreak of TB and DR-TB in a large variety of settings (16). Although research on MTB transmission, using molecular techniques, has been conducted in the Western Cape $(17)$, Kwazulu-Natal $(18,19)$,
Gauteng, and North West (20) province, similar information has not been recorded for DR-TB isolates from Gauteng, Limpopo, and Mpumalanga provinces. There is, therefore, a paucity of information on epidemiological data based on molecular methods addressing the transmission routes of DR-TB strains. This merits attention considering that the country has a high prevalence of HIV/AIDS, a confounding factor for TB resurgence.

The aim of this study was to determine the genetic diversity of resistant MTB isolates, using IS6110 to delineate the dissemination of major phylogenetic clades of the organism in Gauteng, Limpopo, and Mpumalanga regions of South Africa.

\section{MATERIALS AND METHODS}

\section{Study location and population}

The present study was conducted in the TB Laboratory of the DGM Hospital, Gauteng province of South Africa. This province showed a TB prevalence rate of 500/100,000 population in 2006 (21). From January 2004 to December 2006, sputum specimens of all patients $((n=21,913)$ routinely sent for TB analysis to microbiology laboratory of DGM Hospital were included in the study. During the study period, we were aware of only three provinces that had TB diagnostic laboratories, which included Gauteng, Western Cape, and KwazuluNatal. We concentrated on DGM Hospital since it received specimens from other provinces, including Limpopo and Mpumalanga, without diagnostic centres.

\section{Patients' characteristics}

The samples used were routinely collected from patients by hospitals and sent to DGM Hospital for TB diagnosis. Data on the patients, concerning type of specimens and standard demographic information (gender, age, and province), were registered. The study was approved by the Research and Ethics Committee of the University of Venda, South Africa. Informed consent was not obtained from the subjects.

\section{Bacterial isolates}

All specimens were processed and cultured in the BacT/Alert 3D (BioMérieux, Durham, NC, USA) system. Positive cultures were stained with Ziehl Neelsen and confirmed with the AccuProbe DNA hybridization assay (Gen-Probe, USA) according to the manufacturer's instructions. Isolates were then advanced for susceptibility testing and sequencing of katG and rpoB genes $(22,23)$. The 
isolates of MTB analyzed in this study represent all available isolates obtained from patients of Limpopo, Mpumalanga, and Gauteng province, attending DGM Hospital between January 2004 and December 2006. The TB laboratory of DGM Hospital serves as one of the major TB laboratories situated in Gauteng province of South Africa. All the isolates were examined for their susceptibility to isoniazid (INH), ethambutol (EMB), streptomycin (SM), and rifampicin (RIF) following instructions of MGIT 960 system (MGITs; Becton Dickinson Microbiology systems, Sparks, MD, USA). Three hundred thirty-eight resistant strains of $M$. tuberculosis were obtained from 21,913 patients between January 2004 and December 2006. Of all the resistant strains obtained, 97 (28.7\%) were from Gauteng, 32 (9.5\%) from Limpopo, and 209 (61.8\%) from Mpumalanga province. The provinces share borders with one another, with Mpumalanga situated in the Southeast of Limpopo and East of Gauteng, and Limpopo in the North of Gauteng.

\section{Extraction of DNA}

The MGIT 960 cultures were heat-inactivated at $80{ }^{\circ} \mathrm{C}$ for 1 hour before DNA extraction was performed in a biosafety level 2 laminar flow cabinet as previously described $(22,24)$. Briefly, growth from the MGIT 960 system was suspended in $6 \mathrm{~mL}$ of DNA extraction buffer (5\% monosodium glutamate, $50 \mathrm{mM}$ Tris- $\mathrm{HCl}, \mathrm{pH} 7.0$ and $25 \mathrm{mM}$ EDTA) in a sterile $50-\mathrm{mL}$ polypropylene tube which contained approximately thirty $5-\mathrm{mm}$ glass balls. The bacterial clumps were disrupted by vigorous shaking and vortexing. Five hundred microlitre of lysozyme (Amersham Biosciences, Greece) and $10 \mu \mathrm{L}$ of RNAseA (Amersham Biosciences, Greece) were added to the tube. The contents of the tube were mixed by gentle inversion and then incubated at $37^{\circ} \mathrm{C}$ for 2 hours. After incubation, $600 \mu \mathrm{L}$ of $10 \times$ Proteinase K buffer and $150 \mu \mathrm{L}$ of Proteinase K (Amersham Biosciences, Greece) were added. The sample was gently mixed (inverting the tube a few times) and then incubated overnight at $45{ }^{\circ} \mathrm{C}$. Proteins were removed by phenol/chloroform and chloroform/isoamyl-alcohol extraction method (25). DNA was then precipitated with the addition of $600 \mu \mathrm{L}$ of $3 \mathrm{M}$ sodium acetate $(\mathrm{pH} 5.5)$ and $7 \mathrm{~mL}$ of cold $\left(-20^{\circ} \mathrm{C}\right)$ isopropanol. The precipitated DNA was washed with $1 \mathrm{~mL}$ of $70 \%$ ethanol for approximately 1 minute. DNA was then air-dried and resuspended in $30 \mu \mathrm{L}$ in TE buffer $(10 \mathrm{mM}$ Tris, 1 mM EDTA, pH 8.0).
Typing of M. tuberculosis strains, using IS6 | / 0

DNA was extracted using the phenol/chloroform method as described earlier $(24,25)$. RFLP was performed using the standardized IS6110 technique as described previously (15). The extracted genomic DNA was restricted with $P v u$ II (20) in a reaction mix (final volume $30 \mathrm{~mL}$ ) consisting of $3 \mu \mathrm{g}$ of genomic DNA, and 15 units of $P v u$ II in $3 \mu \mathrm{L}$ of the prescribed restriction buffer (Amersham biosciences, Greece). The restriction mix was incubated overnight $( \pm 16 \mathrm{~h})$ at $37^{\circ} \mathrm{C}$. At the end of digestion, the reaction was incubated at $65^{\circ} \mathrm{C}$ for 10 minutes to inactivate any remaining enzyme activity. Restricted products were resolved on a $0.8 \%$ agarose at constant voltage of 40 in 1X TBE buffer for 24 hours. The probe used for hybridization was generated by PCR, using primers INS1 (5 CGT GAG GGC ATC GAG GTG GC 3) and INS2 (5/ GCG TAG GCG TCG GTG ACA AA 3') labelled with horseradish peroxidase $\left(\mathrm{ECL}^{\mathrm{tm}}\right.$ direct nucleic acid labelling and detection kit, Amersham, UK); hybridization and detection were carried out as per manufacturer's instructions.

We restricted the analysis to the isolates with 5 or more bands because isolates with few or no copies of the IS6110 element cannot be reliably classified by this method (26). IS6110 fingerprints were analyzed visually as described earlier (27). Recent transmission was considered likely if an isolate matched at least one other by identical or near-identical criteria. 'Identical' isolates were characterized by equal number of bands on gel electrophoresis, following digestion by restriction endonuclease; all such bands had to have matching molecular weights. 'Near-identical' isolates were characterized by difference of a single band (addition or loss of a single band). RFLP patterns were grouped from 1 to 20 based on the number of IS6110 band. A cluster was defined as a group of two or more patients with drug-resistant MTB strains whose fingerprints were identical with respect to both number and the size of all bands. We used the $\mathrm{n}-1$ method to estimate continuing transmission. The method is based on the assumption that one case per cluster is due to reactivation and that this 'index' infectious case gives rise to other cases in the cluster either by infecting them directly or infecting a secondary case that then infects other members of the cluster. It calculates the number of recently-transmitted cases by summing within clusters after reducing each cluster-size by one giving the transmission dynamics (28). It is calculated by the following formula:

Total number of strains in clusters [Number of clusters]/ Total number of strains 


\section{RESULTS}

\section{Study location and patients' characteristics}

DGM Hospital is a 1,200-bed tertiary referral hospital attached to the Medunsa Campus of the University of Limpopo. HIV status was confirmed for only 64 patients from the hospital-records.

\section{Bacterial isolates}

A total of 1,648/21,913 (7.5\%) MTB isolates were obtained from sputum specimens cultured during the study period. Furthermore, 338/1,648 (20.5\%) resistant strains of MTB from the 1,648 culturepositive strains were obtained. Of these, 97/338 (28.7\%) were from Gauteng, 32/338 (9.5\%) from Limpopo, and 209/338 (61.8\%) from Mpumalanga province. Of the isolates, 33 (63.5\%) were MDR, 6 (11.5\%) resistant to two drugs, $2(3.8 \%)$ resistant to three drugs, and $11(21.1 \%)$ resistant to one drug.

\section{|S6 | | 0 RFLP clustering}

The copy number of IS6110 in each of the isolates was determined from the number of bands hybridizing with the probe, and the copies varied from 1 to 24 . Seven of the 338 strains $(2.07 \%)$ had less than 5 bands. Most strains (331/338, 97.9\%) carried 5 or more copies of IS6110 (Figure 1 and 2). Of the 331 strains, 279 (84.3\%) had unique RFLP patterns. Twenty-two clusters (designated A-V) made up of $52(15.7 \%)$ strains were observed (Table). Thirty-two stains (61.5\%) of the clustered 52 were from Mpumalanga, 16/52 (30.8\%) from Gauteng, and 4/52 (7.7\%) from Limpopo province. The minimum estimate for the proportion of resistant TB that was due to transmission is $9.06 \%$ $(52-22=30 / 331) \times 100$ while the diversity was $90.9 \%$ $(279+22 / 331) \times 100$ as previously defined (29).

\section{Epidemiological investigation of fingerprint groups}

The largest cluster comprised seven patients with drug-resistant TB strains, of which 4 were from Mpumalanga, 2 from Gauteng, and 1 from Limpopo. Five of these patients were male, and two were female. The second cluster was made up of 4 DR-TB strains: two each were isolated from patients who were from Mpumalanga and Limpopo province. One cluster harboured three DR-TB strains isolated from male patients, of whom two were from Mpumalanga and one from Gauteng. The remaining 19 clusters comprised two DR-TB strains isolated from patients who were from Gauteng, Mpumalanga and Limpopo province. The ages of the patients ranged from 10 to 69 years (Table).

\section{Relationship of cluster and resistance}

The drug-resistance patterns of the strains clustered in different fingerprint groups were not similar. The

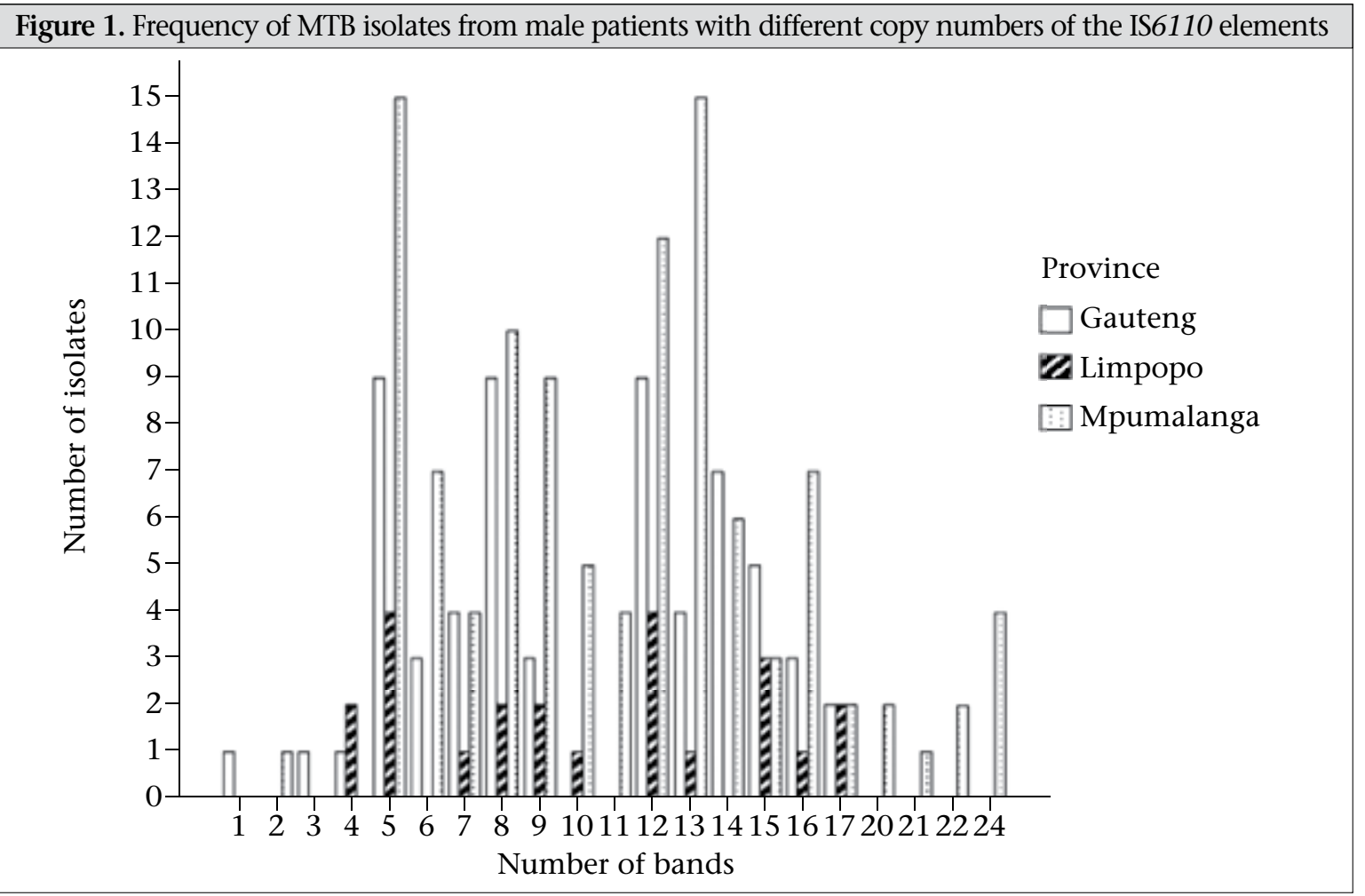




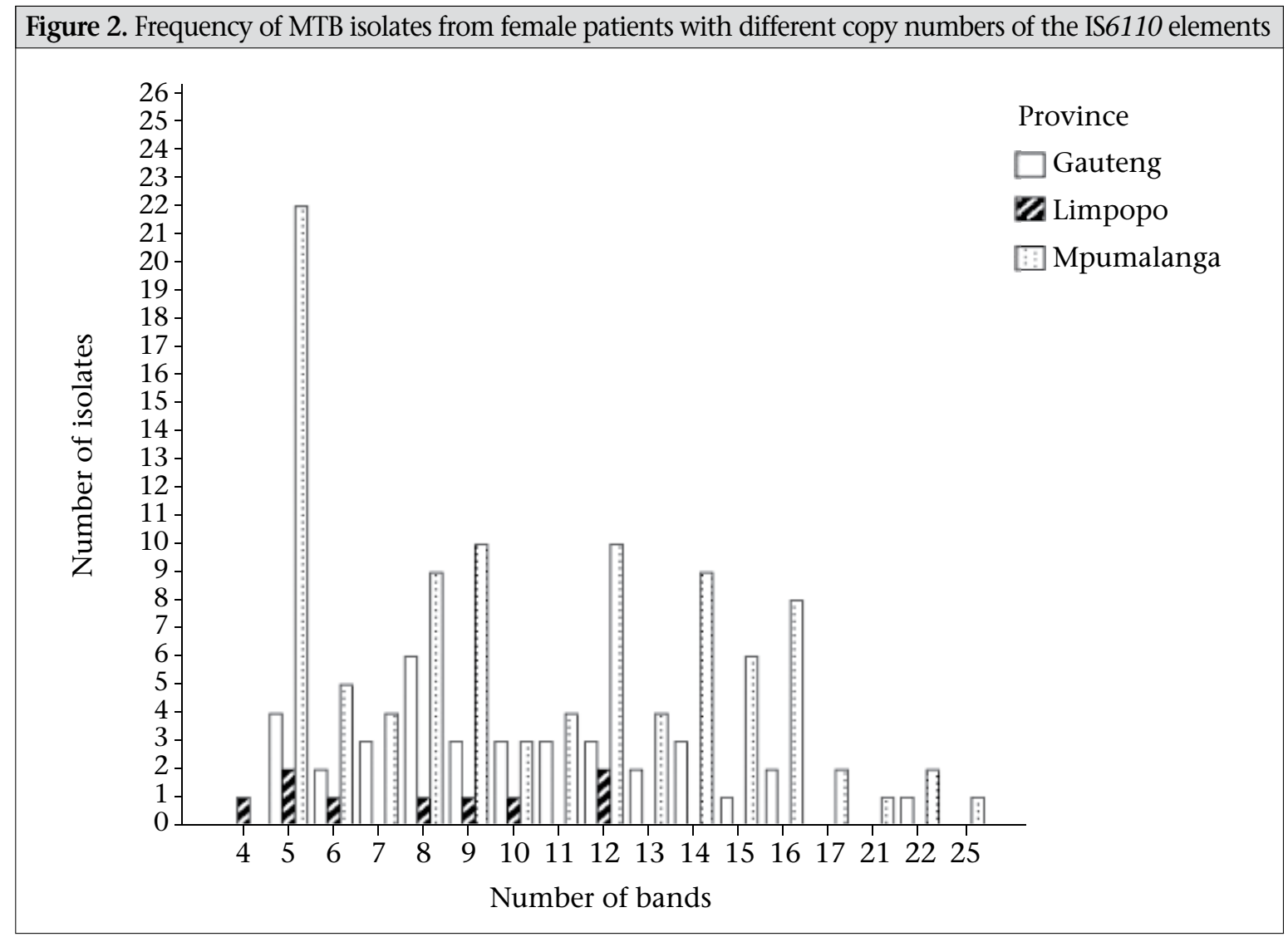

highest number of bands corresponding to 20 was noted for cluster $\mathrm{D}$ while the lowest made up of 5 bands occurred in strains from cluster $\mathrm{O}$ and $\mathrm{P}$. However, band-sizes of 7, 9, 10, 11, 12, 14, 15, 18, and 19 were also noted. There were differences in the sizes of the individual bands (Figure 3).

\section{PCR and sequencing}

Sequencing of the PCR products on the rpoB gene hotspot region showed nucleotide substitution at codon 516 (GAC to GTC) in 44.7\% (72/161) and codon 526 causing a codon change at CAC to GTC in 50.3\% (81/161) of $47.6 \%(161 / 338)$ RIF-resistant isolates studied. One isolate $(0.6 \%, 1 / 161)$ showed the mutation in codon 512 AGC to ACC, 515 ATG to CAT, 516 GAC to GTC, 517 CAG to CCA, 518 AAC to GAA, 519 AAC to CAA, 525 ACC to CAC, $526 \mathrm{CAC}$ to GAC, 529 CGA to CCC, 530 CTG to CCG, 531 TCG to TTG, 532 GCG to CGG, and 533 CTG to CGC in the rpoB region. Overall, 17 different mutations were observed: $29.4 \%(5 / 17)$ single, $64.7 \%(11 / 17)$ double, and 5.9\% (1/17) triple mutations.

In total, $60.3 \%(204 / 338)$ MTB isolates were resistant to INH. Sequencing of the INH-resistant isolates showed a nucleotide substitution at codon
315 in $90.1 \%(184 / 204)$ of the resistant isolates, of which 125/184 (67.9\%) had a codon change from AGC to ACC, 38/184 (20.6\%) had a change from AGC to AAC, and 21/184 (11.4\%) changed from AGC to ACA. A mutation at codon 314 (ACC to CCC) of 20/204 isolates contributed $9.8 \%$ of INH resistance (Table).

\section{DISCUSSION}

IS6110-based DNA fingerprinting of MTB has proven to be highly effective in detecting the source of infection and route of transmission and in simplifying diagnosis of the outbreak (30). In this study, we utilized IS6110 to determine the genetic diversity of drug-resistant MTB isolates from the DGM Hospital in South Africa.

Of the 338 resistant strains (209 from Mpumalanga, 32 from Limpopo, and 97 from Gauteng), $7(2.07 \%)$ showed fewer than 5 copies of IS6110. Similar results $(2.39 \%)$ were obtained in isolates from Germany (31), 5\% in isolates from Rio de Janeiro, Brazil (15), and 8\% strains from East Azerbaijan, Iran (32). However, the number of strains with low-copy number of IS6110 in our study is lower $(2.07 \%)$ than that observed in regions, such as Poland-12\% (33), Delhi, India-18.3\% (34), and 


\begin{tabular}{|c|c|c|c|c|c|c|}
\hline Group & Gender & Age & $\begin{array}{l}\text { Drug resistance } \\
\text { pattern }\end{array}$ & $k a t \mathrm{G}$ & rpoB & Province \\
\hline \multirow[t]{7}{*}{ A } & Male & 33 & INH, RIF & Thr315 & Thr512, Val516 & Mpumalanga \\
\hline & Male & 25 & $\mathrm{INH}$ & Thr315 & WT & Mpumalanga \\
\hline & Female & 35 & INH, RIF, EMB, SM & $\operatorname{Arg} 315$ & Gly516, Asp526 & Mpumalanga \\
\hline & Female & 26 & INH, RIF, EMB, SM & Arg315 & Gly516, Asp526, Tyr522 & Mpumalanga \\
\hline & Male & 47 & EMB & WT & WT & Gauteng \\
\hline & Male & 29 & INH, RIF, EMB, SM & Asn315 & His525, Tyr522 & Gauteng \\
\hline & Male & 30 & INH, RIF, EMB & Thr315 & His525 & Limpopo \\
\hline \multirow[t]{4}{*}{ B } & Male & 53 & SM & WT & WT & Mpumalanga \\
\hline & Male & 26 & INH, RIF, EMB, SM & Thr315 & Thr512, Asp526, Tyr522 & Mpumalanga \\
\hline & Male & 51 & INH & Ile315 & WT & Limpopo \\
\hline & Female & 34 & INH, RIF & Ile315 & Thr512, Asp526, Arg532 & Limpopo \\
\hline \multirow[t]{3}{*}{$\mathrm{C}$} & Male & 18 & INH, RIF, EMB, SM & Thr315 & Gln518 & Mpumalanga \\
\hline & Male & 60 & INH, RIF, EMB & $\operatorname{Arg} 315$ & Asp526 & Mpumalanga \\
\hline & Male & 29 & INH, RIF, SM & Thr315 & Thr512, His515, Val516 & Gauteng \\
\hline \multirow[t]{2}{*}{$\mathrm{D}$} & Male & 37 & INH, RIF, SM & Arg315 & Thr512, His515, Val516 & Mpumalanga \\
\hline & Male & 54 & INH, RIF, EMB, SM & Pro314,Thr315 & Gly516 & Mpumalanga \\
\hline \multirow[t]{2}{*}{$\mathrm{E}$} & Female & 18 & INH, RIF, SM & Thr315 & Thr512, Val516 & Gauteng \\
\hline & Female & 69 & SM & WT & WT & Limpopo \\
\hline \multirow[t]{2}{*}{$\mathrm{F}$} & Male & 41 & INH, RIF, EMB, SM & $\operatorname{Arg} 315$ & Thr512, Asp526, Arg532 & Limpopo \\
\hline & Male & 44 & INH & Arg315 & WT & Mpumalanga \\
\hline \multirow[t]{2}{*}{ G } & Male & 35 & SM & WT & WT & Mpumalanga \\
\hline & Female & 37 & INH, SM & Thr315 & WT & Gauteng \\
\hline \multirow[t]{2}{*}{$\mathrm{H}$} & Male & 44 & INH, SM & Thr315 & WT & Gauteng \\
\hline & Male & 33 & INH, RIF, EMB, SM & Pro314 & Gly516, Arg532 & Mpumalanga \\
\hline \multirow[t]{2}{*}{ I } & Female & 22 & INH, RIF, EMB & Thr315 & Arg533 & Gauteng \\
\hline & Male & 29 & $\mathrm{INH}$ & Thr315 & WT & Mpumalanga \\
\hline \multirow[t]{2}{*}{$\mathrm{J}$} & Male & 33 & INH, RIF, EMB, SM & Thr315 & Thr512, Asp526, Arg532, & Mpumalanga \\
\hline & Male & 42 & INH, RIF & Pro314 & Gly516, Arg533 & Mpumalanga \\
\hline \multirow[t]{2}{*}{ K } & Female & 32 & $\mathrm{INH}$ & Pro314 & WT & Mpumalanga \\
\hline & Male & 10 & INH, RIF & Thr315 & Pro529 & Gauteng \\
\hline \multirow[t]{2}{*}{$\mathrm{L}$} & Male & 50 & INH & Thr315 & WT & Mpumalanga \\
\hline & Male & 31 & INH, RIF & Pro314 & Thr512, Arg532, Gln518 & Mpumalanga \\
\hline \multirow[t]{2}{*}{ M } & Male & 21 & INH, RIF, EMB, SM & Asn315 & Glu519 & Mpumalanga \\
\hline & Male & 41 & INH, EMB, SM & Thr315 & Pro529, Glu519 & Mpumalanga \\
\hline \multirow[t]{2}{*}{$\mathrm{N}$} & Male & 34 & EMB, SM & WT & WT & Gauteng \\
\hline & Male & 26 & INH, RIF, EMB, SM & Arg315 & Gln518, Cys531 & Mpumalanga \\
\hline \multirow[t]{2}{*}{$\mathrm{O}$} & Male & 33 & INH, RIF, EMB, SM & Thr315 & Pro530, Tyr522 & Mpumalanga \\
\hline & Female & 50 & INH, RIF & Thr315 & Thr512, Pro529, Glu519 & Mpumalanga \\
\hline \multirow[t]{2}{*}{$\mathrm{P}$} & Male & 54 & INH, RIF, SM & Pro314 & Pro529, Glu519 & Mpumalanga \\
\hline & Male & 30 & INH, EMB, SM & Thr315 & Gln518, Cys531 & Mpumalanga \\
\hline \multirow[t]{3}{*}{ Q } & Male & 33 & INH, RIF, EMB, & Thr315 & Tyr522 & Mpumalanga \\
\hline & Male & 28 & INH, RIF, EMB, SM & Thr315 & Gly516, Cys531 & Mpumalanga \\
\hline & & & & & & Contd. \\
\hline
\end{tabular}




\begin{tabular}{|ccccccc|}
\hline Table-contd. & \multicolumn{7}{c|}{ } \\
\hline Group & Gender & Age & $\begin{array}{c}\text { Drug resistance } \\
\text { pattern }\end{array}$ & katG & rpoB & Province \\
\hline R & Female & 18 & INH, RIF & Thr315 & Asp530 & Gauteng \\
& Male & 60 & INH, RIF, EMB & Thr315 & Arg532 & Mpumalanga \\
S & Male & 31 & INH, SM & Asn315 & His515 & Mpumalanga \\
& Female & 45 & INH & Thr315 & Val516, Gln518, Glu519 & Gauteng \\
T & Male & 37 & INH, RIF, SM & Thr315 & Asp526, Arg532, Arg533 & Mpumalanga \\
& Male & 31 & INH, RIF & Asp315 & Val516, Asp526 & Mpumalanga \\
U & Male & 29 & INH, RIF, EMB, SM & Pro314 & Asp526, Gln518 & Gauteng \\
& Male & 37 & INH, SM & Thr315 & Pro529 & Gauteng \\
V & Female & 21 & INH, RIF, EMB, SM & Thr315 & Arg532 & Mpumalanga \\
& Female & 34 & INH, EMB & Thr315 & WT & Mpumalanga \\
\hline
\end{tabular}

Figure 3. Representative examples of IS6110 RFLP patterns associated with 22 high-copy clusters $(\mathrm{A}-\mathrm{V})$. The number of strains in each cluster is shown at the bottom of each pattern. The last lane shows reference strain

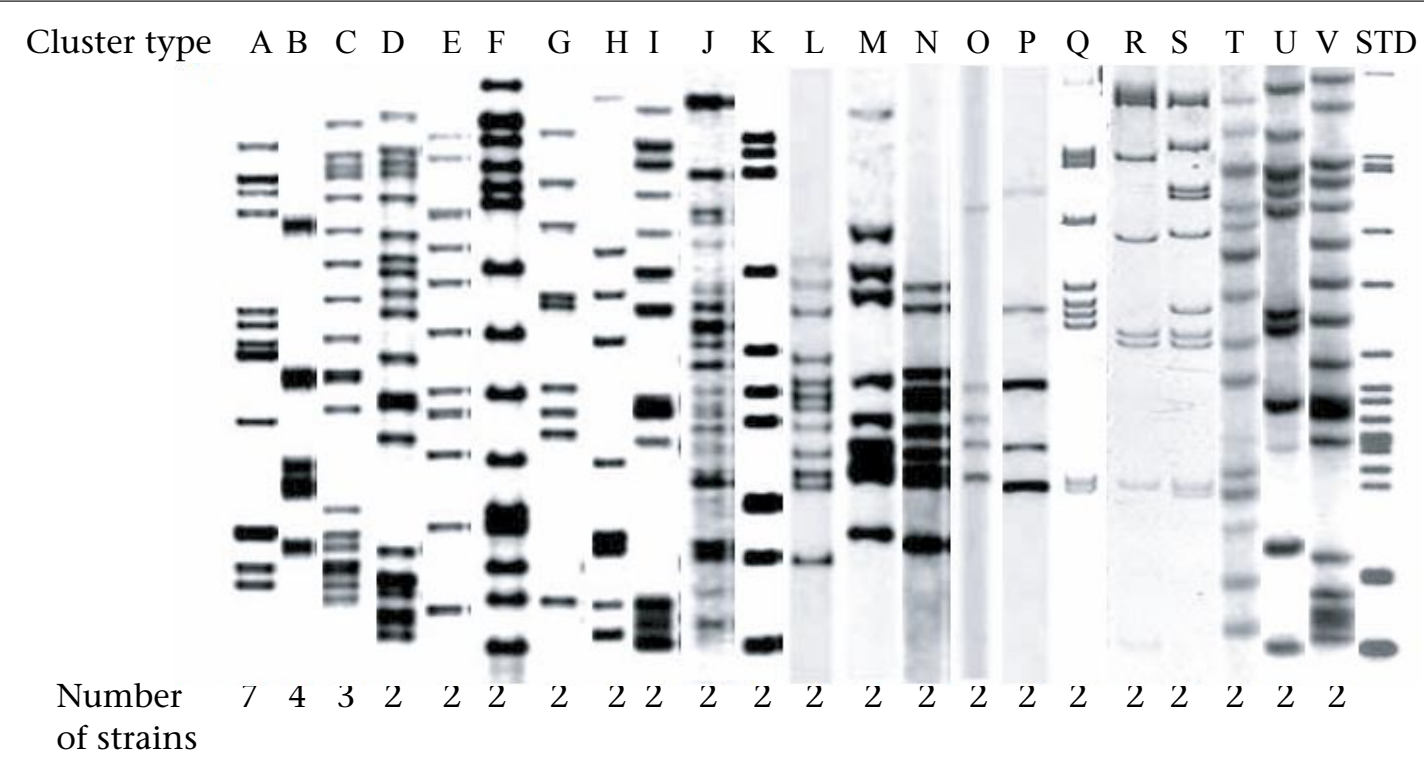

Germany-11.9\% (29). Many reports on epidemiological studies of TB use a secondary typing to increase the accuracy of indicating epidemiological links. In the case of IS6110-RFLP patterns, this is considered necessary, mainly when dealing with MTB populations presenting a high proportion of strains with low-copy number (35). In light of these findings, IS6110 can be used without additional typing markers for this area.

Recent population-based studies have shown that patients with MTB strains showing identical IS6110 fingerprint patterns are likely to have become infected recently (36). In our study, 22 fingerprint groups with identical patterns were found. Most of these patterns consisted of 2 patients, indicating that tuberculosis transmission in this region may be described as a micro-epidemic. In the past two decades, the rare occurrence of drug-resistant strains was ascribed to the conviction that drug-resistant MTB strains were less virulent (37). However, studies have shown that drug-resistant strains do not differ from drug-sensitive strains in their ability to create infection or disease, and that drug-resistant strains contribute substantially to the increase of tuberculosis (38-41).

Mpumalanga is one of the poorest provinces in South Africa, and people living in the province are of low socioeconomic status (42). MDR-TB cases of $1.99 \%$ were reported in the province in 2004 (3). The cases increased to $2.64 \%$ in 2006 and decreased 
drastically to $1.17 \%$ in April 2007. This is highly worrisome as it may mean that many patients with MDR-TB are not being diagnosed. This region might be a risk-zone because most (65.4\%) of the clustered isolates were obtained from this zone compared to the other investigated provinces. This corroborates previous works in which the region was defined as a risk-zone for tuberculosis clustering (43). However, clustering could have been overestimated as more samples analyzed (61.8\%) were from Mpumalanga than from Gauteng and Limpopo while other provinces were not investigated. Gauteng is the richest province in South Africa (44). This province showed an incidence rate of 500/100,000 in 2006 compared to $722 / 100,000$ for overall South Africa.

In a study done in the same laboratory, Rampe et al. (20) reported a total number of clustering of 0.47 , indicating a transmission rate of $47 \%$. However, that study focused on isolates from the locations surrounding DGM Hospital (previously called Ga-Rankuwa Hospital), and the study had a lower sample-size. We observed a 52-22=30/331 (0.096) clustering among resistant $M$. tuberculosis isolates, indicating recent transmission rate of about $9 \%$. We also observed that, besides failures of tuberculosis treatment, transmission of drug-resistant tuberculosis contributes to the problem of drug resistance in South Africa. At least $91 \%$ of the problem of drug resistance in this population could be the product of acquired resistance. However, in the absence of clinical data (retreatment or primary resistance) on the patients from whom these strains were isolated, it is difficult to conclude whether they represent fresh cases or cases of reactivation. In a mixed population, the degree of DNA polymorphism is greater (15) - a situation common in South Africa. In South Africa, people also travel to other provinces looking for jobs, which may introduce new strains into otherwise unaffected areas, leading to high genetic diversity.

In our study, strains that clustered demonstrated resistance to the same antitubercular drug with or without resistance to additional drugs. The likelihood is that an additional resistance was acquired after transmission occurred. The close relationship of the strains clustered in different groups (e.g. A, O, and $\mathrm{P}$ ) was further confirmed by the overall good association between IS6110 and data on drug resistance. This report of clustered strains further confirms that drug-resistant MTB isolates can be transmitted. Furthermore, it should be noted that the study was performed using isolates obtained from one hospital and because of disease transmission which emanated from the clusters and the time it takes for MTB to grow (6-8 weeks); a study using a larger population should be performed to evaluate the real clustering rate.

One of the risk factors identified in our study was the male gender. Of the 52 clustered strains, 39 (75\%) were from the male gender. A study in Paris showed the same results (45). However, a study in Iran showed more clustering in females than in males (30). Although few epidemiological links were confirmed in this study, demographic and behavioural risk factors, such as body mass index, alcohol consumption, and smoking, have been identified as the causes of tuberculosis clustering elsewhere (46). This is understandable as smoking and alcohol consumption may be proxies for frequenting locations that puts one at risk of close contact with infectious individuals, such as neighborhood bar (46).

Being a pro-drug that requires activation by catalase peroxidase enzyme produced by MTB, INH plays an important role in treating latent MTB infection (LTBI), for prevention of active disease and the subsequent TB transmission. It is also a cornerstone of the modern short-course chemotherapy for tuberculosis. Mutation in the gene producing this enzyme will render the organism resistant to INH. Codon 315 mutations were shown to be associated with high-level resistance to INH. Results obtained from this study suggest that serine substitution at codon 315 of the $k a t \mathrm{G}$ gene $(57.7 \%)$ is a characteristic of local INH-resistant strains and, therefore, can serve as a genetic marker for INH-resistance in our region. The high proportion of katG 315Thr-resistant isolates in this study had mutation in the rpoB gene (46\%), which was related to RIF resistance reported in South Africa (21).

\section{Conclusions}

Our results indicate that transmission of drugresistant strains may contribute to the emergence of drug-resistant tuberculosis in South Africa-a finding with profound clinical and epidemiological significance.

\section{ACKNOWLEDGEMENTS}

We would like to thank the National Research Foundation of South Africa for providing financial support for the study, the staff members at DGM Hospital for making available their facilities and technical assistance. 


\section{REFERENCES}

1. World Health Organization. Guidelines for surveillance of drug resistance in tuberculosis. 4th ed. Geneva: World Health Organization, 2009. 83 p. (WHO/ $\mathrm{HTM} / \mathrm{TB} / 2009.422$ ).

2. World Health Organization. Global tuberculosis control: surveillance, planning, financing; WHO report 2007. Geneva: World Health Organization, 2007. 270 p. (WHO/HTM/TB/2007.376).

3. Republic of South Africa. Department of Health. Tuberculosis strategic plan for South Africa, 2007-2011. Gauteng: Department of Health, Republic of South Africa, 2007. 66 p. (http://www.info.gov.za/view/ DownloadFileAction?id=72544)

4. Day C, Gray A. Health and related indicators. Chapter 17. In: Ijumba P, Barron P, editors. South African Health Review 2005. Durban: Health Systems Trust, 2005:248-367.

5. World Health Organization. Global tuberculosis control: surveillance, planning, financing: WHO report 2008. Geneva: World Health Organization, 2008. 294 p. (WHO/HTM/TB/2008.393).

6. Fattorini L, Migliori GB, Cassone A. Extensively drugresistant (XDR) tuberculosis: an old and new threat. Ann Ist Super Sanita 2007;43:317-9.

7. World Health Organization. What is DOTS? A guide to understanding the WHO-recommended TB control strategy known as DOTS. Geneva: World Health Organization, 1999. 33 p. (WHO/CDS/CPC/ TB/99.270).

8. Silva MSN, Senna SG, Ribeiro MO, Valim ARM, Telles MA, Kritski A et al. Mutations in $k a t G$, inhA, and $a h p C$ genes of Brazilian isoniazid-resistant isolates of Mycobacterium tuberculosis. J Clin Microbiol 2003;41:4471-4.

9. Zheltkova EA, Chernousova LN, Smirnova TG, Andreevskaia SN, Yates M, Drobniewskiı̌ F. [Molecular genotyping of Mycobacterium tuberculosis strains isolated from patients in the Samara region by the restriction DNA fragment length polymorphism]. $\mathrm{Zh}$ Mikrobiol Epidemiol Immunobiol 2004(5):39-43. [Russian]

10. Kurabachew M, Enger $\varnothing$, Sandaa RA, Lemma E, Bjorvatn $\mathrm{B}$. Amplified ribosomal DNA restriction analysis in the differentiation of related species of mycobacteria. J Microbiol Methods 2003;55:83-90.

11. Pardini M, Iona E, Varaine F, Karakozian H, Arzumanian H, Brunori L et al.; Long-Drug Study Group. Mycobacterium tuberculosis drug resistance, Abkhazia. Emerg Infect Dis 2005;11:501-3.

12. Kapp C. XDR tuberculosis spreads across South Africa. Lancet 2007;369:729.

13. Moström P, Gordon M, Sola C, Ridell M, Rastogi N.
Methods used in the molecular epidemiology of tuberculosis. Clin Microbiol Infect 2002;8:694-704.

14. Fandinho FC, Kritski AL, Hofer C, Júnior Conde H, Ferreira RM, Saad MH et al. RFLP patterns and risk factors for recent tuberculosis transmission among hospitalized tuberculosis patients in Rio de Janeiro, Brazil. Trans R Soc Trop Med Hyg 2000;94:271-5.

15. van Embden JD, Cave MD, Crawford JT, Dale JW, Eisenach KD, Gicquel B et al. Strain identification of Mycobacterium tuberculosis by DNA fingerprinting: recommendations for a standardized methodology. $J$ Clin Microbiol 1993;31:406-9.

16. Small PM, McClenny NB, Singh SP, Schoolnik GK, Tompkins LS, Mickelsen PA. Molecular strain typing of Mycobacterium tuberculosis to confirm cross-contamination in the mycobacteriology laboratory and modification of procedures to minimize occurrence of falsepositive cultures. J Clin Microbiol 1993;31:1677-82.

17. van Rie A, Warren RM, Beyers N, Gie RP, Classen CN, Richardson $\mathrm{M}$ et al. Transmission of a multidrugresistant Mycobacterium tuberculosis strain resembling "strain W" among noninstitutionalized, human immunodeficiency virus-seronegative patients. $J$ lnfect Dis 1999;180:1608-15.

18. Wilkinson D, Pillay M, Crump J, Lombard C, Davies GR, Sturm AW. Molecular epidemiology and transmission dynamics of Mycobacterium tuberculosis in rural Africa. Trop Med Int Health 1997;2:747-53.

19. Wilkinson D, Crump J, Pillay M, Sturm AW. Nosocomial transmission of tuberculosis in Africa documented by restriction fragment length polymorphism. Trans R Soc Trop Med Hyg 1997;91:318.

20. Rampe AK, Hess A, Clay CK, Du Toit D. Characterization of Mycobacterium tuberculosis strains isolated at Ga-Rankuwa Hospital by fingerprinting with insertion sequence IS6110. South Afr J Epidemiol Infect 2004;19:96-100.

21. Schierhout G, Johnson S, Delate R. First HIV and AIDS National Communication Survey 2006: findings from Gauteng Province. Pretoria: Johns Hopkins Health and Education, 2008. 24 p. (http://www.hda. co.za/documents/provincial_analyses/gauten.pdf)

22. Tang X, Morris SL, Longone JJ, Bockstahler LE. Microarray and allele specific PCR detection of point mutations in Mycobacterium tuberculosis genes associated with drug resistance. J Microbiol Methods 2005;63:318-30.

23. Green E, Obi LC, Nchabeleng M, de Villiers BE, Sein PP, Letsoalo T et al. Molecular characterisation of resistant Mycobacterium tuberculosis isolates from Dr George Mukhari Hospital, Pretoria, South Africa. South Afr J Epidemiol Infect 2008;23:11-4.

24. Van Der Zanden AG, Te Koppele-Vije EM, Vijaya 
Bhanu N, Van Soolingen D, Schouls LM. Use of DNA extracts from Ziehl-Neelsen-stained slides for molecular detection of rifampin resistance and spoligotyping of Mycobacterium tuberculosis. J Clin Microbiol 2003;41:1101-8.

25. Miller SA, Dykes DD, Polesky HF. A simple salting out procedure for extracting DNA from human nucleated cells. Nucleic Acids Res 1988;16:1215.

26. Das S, Paramasivan CN, Lowrie DB, Prabhakar R, Narayanan PR. IS6110 restriction fragment length polymorphism typing of clinical isolates of $\mathrm{Myco}$ bacterium tuberculosis from patients with pulmonary tuberculosis in Madras, South India. Tuber Lung Dis 1995;76:550-4.

27. van Soolingen D, de Haas PE, Hermans PW, Groenen PM, van Embden JD. Comparison of various repetitive DNA elements as genetic markers for strain differentiation and epidemiology of Mycobacterium tuberculosis. J Clin Microbiol 1993;31:1987-95.

28. Murray M, Alland D. Methodological problems in the molecular epidemiology of tuberculosis. Am J Epidemiol 2002;155:565-71.

29. Small PM, Hopewell PC, Singh SP, Paz A, Parsonnet J, Ruston DC et al. The epidemiology of tuberculosis in San Francisco. A population-based study using conventional and molecular methods. $N$ Engl J Med 1994;330:1703-9.

30. Díaz R, Gómez RI, García N, Valdivia JA, van Soolingen D. Molecular epidemiological study on transmission of tuberculosis in a hospital for mentally handicapped patients in Havana, Cuba. J Hosp Infect 2001;49:30-6.

31. Niemann S, Rüsch-Gerdes S, Richter E. IS6110 fingerprinting of drug-resistant Mycobacterium tuberculosis strains isolated in Germany during 1995. J Clin Microbiol 1997;35:3015-20.

32. Asgharzadeh M, Shahbabian K, Majidi J, Aghazadeh AM, Amini C, Jahantabi AR et al. IS6110 restriction fragment length polymorphism typing of Mycobacterium tuberculosis isolates from East Azerbaijan Province of Iran. Mem Inst Oswaldo Cruz 2006;101:517-21.

33. Dela A, Sajduda A, Pawłowska I, Dziadek J. Molecular characterization of Mycobacterium tuberculosis isolates from Łódź, Poland: analysis by IS6110 restriction fragment length polymorphism and double-repetitive-element PCR. J Infect 2006;52:346-53.

34. Bhanu NV, van Soolingen D, van Embden JD, Dar L, Pandey RM, Seth P. Predominace of a novel Mycobacterium tuberculosis genotype in the Delhi region of India. Tuberculosis (Edinb) 2002;82:105-12.

35. Rhee JT, Tanaka MM, Behr MA, Agasino CB, Paz EA, Hopewell PC et al. Use of multiple markers in population-based molecular epidemiologic studies of tuber- culosis. Int J Tuberc Lung Dis 2000;4:1111-9.

36. Luciani F, Francis AR, Tanaka MM. Interpreting genotype cluster sizes of Mycobacterium tuberculosis isolates typed with IS6110 and spoligotyping. Infect Genet Evol 2008;8:182-90.

37. Cohn ML, Davis CL. Infectivity and pathogenicity of drug-resistant strains of tubercle bacilli studied by aerogenic infection of guinea pigs. Am Rev Respir Dis 1970;102:97-100.

38. van Soolingen D, de Haas PE, van Doorn HR, Kuijper E, Rinder H, Borgdorff MW. Mutations at amino acid position 315 of the katG gene are associated with high-level resistance to isoniazid, other drug resistance, and successful transmission of Mycobacterium tuberculosis in The Netherlands. I Infect Dis 2000;182:1788-90.

39. Toungoussova OS, Caugant DA, Sandven P, Mariandyshev AO, Bjune G. Impact of drug resistance on fitness of Mycobacterium tuberculosis strains of the W-Beijing genotype. FEMS Immunol Med Microbiol 2004;42:281-90.

40. Sajduda A, Brzostek A, Popławska M, Rastogi N, Sola C, Augustynowicz-Kopec E et al. Molecular epidemiology of drug-resistant Mycobacterium tuberculosis strains isolated from patients with pulmonary tuberculosis in Poland: a 1-year study. Int J Tuberc Lung Dis 2004;8:1448-57.

41. Mpumalanga. Health Department. Strategic plan for Mpumalanga Provincial Health Department for 2003/04-2005/06. Mpumalanga: Health Department, 2003. $102 \mathrm{p}$.

42. Verver S, Warren RM, Munch Z, Vinnycky E, van Helden PD, Richardson $\mathrm{M}$ et al. Transmission of tuberculosis in a high incidence urban community in South Africa. Int J Epidemiol 2004;33:351-7.

43. Asgharzadeh M, Shahbabian K, Majidi J, Aghazadeh AM, Amini C, Jahantabi AR et al. IS6110 restriction fragment length polymorphism typing of Mycobacterium tuberculosis isolates from East Azerbaijan Province of Iran. Mem Inst Oswaldo Cruz 2006;101:517-21.

44. Gutierrez MC, Vincent V, Aubert D, Bizet J, Gaillot $\mathrm{O}$, Lebrun L et al. Molecular fingerprinting of $\mathrm{Myco}$ bacterium tuberculosis and risk factors for tuberculosis transmission in Paris, France, and surrounding area. J Clin Microbiol 1998;36:486-92.

45. Munch Z, Van Lill SW, Booysen CN, Zietsman HL, Enarson DA, Beyers N. Tuberculosis transmission patterns in a high-incidence area: a spatial analysis. Int J Tuberc Lung Dis 2003;7:271-7.

46. Harling G, Ehrlich R, Myer L. The social epidemiology of tuberculosis in South Africa: a multilevel analysis. Soc Sci Med 2008;66:492-505. 